\title{
Upregulation of microRNA-18b induces phosphatase and tensin homolog to accelerate the migration and invasion abilities of ovarian cancer
}

\author{
XIAOFANG HAN ${ }^{1,2}$, YAN ZHANG ${ }^{1}$, DONG WANG ${ }^{1}$, XINYUN FU $^{1},{\text { MEIQING } \text { LI }^{1} \text { and AIMING WANG }}^{1,3}$ \\ ${ }^{1}$ Department of Obstetrics and Gynecology, Southern Medical University, Guangzhou, Guangdong 510515; \\ ${ }^{2}$ Department of Reproduction, Shanxi Provincial People's Hospital, Taiyuan, Shanxi 030012; \\ ${ }^{3}$ Department of Reproduction, Navy General Hospital, Beijing 100048, P.R. China
}

Received October 26, 2015; Accepted April 13, 2017

DOI: $10.3892 / 01.2017 .6854$

\begin{abstract}
Ovarian cancer (OC) is the most common cause of mortality from malignant gynecological cancers. Its lethality is mainly a result of tumors that are difficult to detect at the early stage and a lack of effective systemic therapy for advanced status cancer. MicroRNAs (miRNAs/miRs) are a category of single-stranded non-coding small RNAs that bind to their target mRNAs, and aberrant expression levels of miRNAs may serve key roles in regulating cell migration and invasion of various types of human cancer. Previous studies have demonstrated that miR-18b may function as an oncogene in numerous types of tumors, but its role and molecular mechanism in OC remained unclear. The present study demonstrated for the first time that miR-18b expression was significantly upregulated in OC tissues and cells. An increased miR-18b expression level was positively associated with tumor grade and lymph node metastasis. An in vitro assay revealed that exogenous inhibition of miR-18b expression may markedly inhibit OC cell migratory and invasive activities, whereas overexpression of miR-18b enhanced cell migratory and invasive abilities. Of note, using in silico methodologies and luciferase reporter assays, it was demonstrated that phosphatase and tensin homolog (PTEN) was a direct target of miR-18b in OC cells. Furthermore, knockdown of miR-18b expression may significantly decrease mRNA and protein expression levels of endogenous PTEN. The results of the present study highlighted that upregulation of miR-18b was involved in OC cell metastasis by directly targeting PTEN. Inhibition of miR-18b may be a novel effective diagnostic and therapeutic measure for OC.
\end{abstract}

Correspondence to: Professor Aiming Wang, Department of Reproduction, Navy General Hospital, 6 Fucheng Road, Haidian, Beijing 100048, P.R. China

E-mail: fbwzzy@163.com

Key words: ovarian cancer, microRNA-18b, migration and invasion, phosphatase and tensin homolog

\section{Introduction}

Ovarian cancer (OC) is the sixth most common malignant gynecological tumor and accounts for 190,000 novel cases every year in the USA (1). Owing to the lack of explicit early symptoms and effective biomarkers for OC monitoring and diagnosis, the overall 5-year survival rate for patients with OC is $<30 \%(2,3)$. Therefore, elucidation of the molecular mechanisms underlying the progression and metastasis of $\mathrm{OC}$ is critical to improve therapeutic effects for patients with OC.

MicroRNAs (miRNAs/miRs) are a class of single-stranded small non-coding RNAs 22 nucleotides in length, which are capable of regulating the expression levels of a number of genes at the transcriptional and post-transcriptional level $(4,5)$. Multiple miRNAs function as potential tumor suppressors or oncogenes due to their fundamental roles in diverse cellular processes of various types of human cancer, including proliferation, migration, invasion and apoptosis (6-11). Currently, numerous miRNAs including miR-126 (12), miR-137 (13), miR-145 (14), miR-148a (15) and miR-498 (16) have been demonstrated as tumor suppressor genes in OC. Conversely, miR-196a (17), miR-200a (18), miR-205 (19), miR-543 (20) and miR-661 (21) have been revealed to function as oncogenes in OC. All these results highlight the involvement of miRNAs in the development and progression of OC.

miR-18b is located on the $\mathrm{X}$ chromosome in the human genome (22). Previous studies have demonstrated that the aberrant expression level of miR-18b may be present in diverse human pathologies, including multiple sclerosis, cardiac hypertrophy and chronic hepatitis B virus infection $(22,23)$. miR-18b has attracted much attention as it is frequently upregulated and acts as a oncogene in human gastric cancer (24), colonic cancer (25), breast cancer (22) and hepatocellular carcinoma (26). However, whether miR-18b is involved in the development and progression of OC remains unclear.

The results of the present study revealed that $\mathrm{miR}-18 \mathrm{~b}$ was significantly upregulated in OC tissues and cell lines in comparison with the normal ovarian counterparts. Furthermore, miR-18b may promote OC cell migration and invasion by directly targeting phosphatase and tensin homolog (PTEN). The result of the present study suggested that miR-18b 
may act as an oncogene and support the utility of miR-18b and PTEN as potential biomarkers that may be promising targets for the treatment of $\mathrm{OC}$.

\section{Materials and methods}

Clinical samples and cell lines. A total of 60 fresh OC tissue samples and 60 matched normal ovarian tissues were collected from 60 patients with OC between December 2008 and December 2014 (mean age, 54.3 \pm 3.7 years) from the Navy General Hospital (Beijing, China). Written informed consent was obtained from all patients for use of tissue samples in the present study. The present study approved by the Ethics Committee of Navy General Hospital. All specimens were frozen immediately in liquid nitrogen until use. Tissue sample characteristics and information are presented in Table I. ES-2 and HO8910 human OC cells, and HOSE human normal ovarian epithelial cells were obtained from the American Type Culture Collection (Manassas, VA, USA).

RNA isolation andreverse transcription-quantitative polymerase chain reaction $(R T-q P C R)$ analysis. Total RNA of OC tissues and cells were extracted using TRIzol ${ }^{\circledR}$ reagent (Invitrogen; Thermo Fisher Scientific, Inc., Waltham, MA, USA), according to the manufacturer's instructions. The cDNA was synthesized by Oligo-dT (Takara Bio, Inc., Otsu, Japan) or specific miRNA stem-loop RT primers (Invitrogen; Thermo Fisher Scientific, Inc.) with $1 \mu \mathrm{g}$ total RNA, according to the manufacturer's protocols. RT-qPCR was performed using an ABI PRISM 7000 Sequence Detection System (Applied Biosystems; Thermo Fisher Scientific, Inc.). The temperature protocol of RT was as follows: $65^{\circ} \mathrm{C}$ for $5 \mathrm{~min}, 4^{\circ} \mathrm{C}$ for $1 \mathrm{~min}, 50^{\circ} \mathrm{C}$ for $50 \mathrm{~min}$ and $85^{\circ} \mathrm{C}$ for $5 \mathrm{~min}$. To assess miR-18b expression levels, RT-qPCR was performed using an NCode ${ }^{\mathrm{TM}}$ EXPRESS SYBR-Green ER ${ }^{\mathrm{TM}}$ miRNA qRT-PCR kit (Invitrogen; Thermo Fisher Scientific, Inc.) with U6 as an internal control. For determination of the PTEN expression level, RT-qPCR was performed using the EmeraldAmp PCR Master mix (Takara Bio, Inc.). The conditions for qPCR were as follows: $98^{\circ} \mathrm{C}$ for $10 \mathrm{~min}$, followed by 45 cycles of $98^{\circ} \mathrm{C}$ for $10 \mathrm{sec}, 60^{\circ} \mathrm{C}$ for $30 \mathrm{sec}$ and $72^{\circ} \mathrm{C}$ for $30 \mathrm{sec}$. The specific primers are presented in Table II. Relative expression levels of miR-18b and PTEN were normalized to those of U6 and GAPDH, respectively, and quantified using the comparative $\mathrm{Cq}$ method with the formula $2^{-\Delta \Delta \mathrm{Cq}}(27)$.

Cell culture and transfection. All cells were maintained in Dulbecco's modified Eagle's medium (Invitrogen; Thermo Fisher Scientific, Inc.) supplemented with $10 \%$ (v/v) fetal bovine serum (FBS) at $37^{\circ} \mathrm{C}$ in a humidified chamber containing $5 \%$ $\mathrm{CO}_{2}$. miR-18b mimic, corresponding mimic negative control, miR-18b inhibitor and corresponding inhibitor negative control were obtained from GenePharm, Inc. (Sunnyvale, CA, USA). Lipofectamine $2000^{\circledR}$ transfection reagent (Invitrogen; Thermo Fisher Scientific, Inc.) was used to transfect either miR-18b mimic or mimic negative control, and either miR-18b inhibitor or inhibitor negative control into ES-2 and HO8910 cells, according to the manufacturer's protocol. After $48 \mathrm{~h}$ of transfection, the efficiency of miR-18b overexpression or knockdown in OC cells was quantified by RT-qPCR analysis prior to in vitro cellular functional experiments.
Protein extraction and western blot analysis. Total proteins of OC cells were collected using radioimmunoprecipitation assay (RIPA) reagents (Beyotime Institute of Biotechnology, Haimen, China), according to the manufacturer's protocol. Cell lysates were washed with PBS three times and incubated with ice-cold RIPA buffer for $30 \mathrm{~min}$ at $4^{\circ} \mathrm{C}$. Subsequently, the cell lysates were centrifuged at $13,000 \mathrm{x} \mathrm{g}$ for $15 \mathrm{~min}$ at $4^{\circ} \mathrm{C}$. Subsequently, SDS-PAGE $(10 \%$ gel; Beyotime Institute of Biotechnology) was used for separating total proteins into equal amounts $(50 \mu \mathrm{g})$, which were transferred onto polyvinylidene fluoride membranes (EMD Millipore, Billerica, MA, USA). Following blocking with 5\% non-fat milk (diluted in TBST) for $1 \mathrm{~h}$ at $37^{\circ} \mathrm{C}$, the membranes were incubated with anti-PTEN antibodies (\#9552; 1:1,000; Santa Cruz Biotechnology, Inc., Dallas, TX, USA) overnight at $4^{\circ} \mathrm{C}$, followed by horseradish peroxidase-conjugated corresponding secondary antibodies (\#7074; 1:2,000; Santa Cruz Biotechnology, Inc.).

Cell migration and invasion assays. Wound healing assays were performed to determine the migratory ability of miR-18b-transfected OC cells. ES-2 and HO8910 cells were seeded at a density of $\sim 8 \times 10^{5}$ cells/well in 6 -well plates and transfected as aforementioned. Following a 6-h transfection period, artificial wounds were created and cell migration images were captured from three randomly selected fields at 0,12 and 16 h using a Leica DM4000B microscope (magnification, x200; Leica Microsystems, Inc., Buffalo Grove, IL, USA). OC cell invasion assays were performed in triplicate using Transwell assays. Briefly, $5 \times 10^{4}$ cells were plated in Dulbecco's modified Eagle's medium (DMEM; Invitrogen; Thermo Fisher Scientific, Inc.) without serum, and DMEM supplemented with $10 \%$ FBS was added as a chemoattractant to the lower chamber. Following incubation for $48 \mathrm{~h}$, cells on top of the filter were removed, and those that migrated to the underside of the filter were stained with Hema-Diff solution (Thermo Fisher Scientific, Inc.) and counted for five random fields/well using a Leica DM4000B microscope (magnification, x200; Leica Microsystems, Inc.).

Luciferase reporter assay. Target sequences were inserted into psiCHECK-2 luciferase reporter vectors (Promega Corporation, Madison, WI, USA) to obtain psiCHECK-2-PTEN-WT recombinant plasmid, which contained the miR-18b-binding sequences at the PTEN mRNA 3'-untranslated region (UTR) region. psiCHECK-2-PTEN-MUT contained sequences with mutations in the putative binding site of PTEN 3'-UTRs and was chemically synthesized by GenePharm, Inc. ES-2 cells $\left(\sim 4 \times 10^{4}\right)$ were seeded in 24-well plates and cultured for $24 \mathrm{~h}$ at $37^{\circ} \mathrm{C}$. Subsequently, cells were co-transfected with $400 \mathrm{ng}$ psiCHECK-2-PTEN (WT) or psiCHECK-2-PTEN mutant (MUT), and 20 pmol miR-18b mimic or miR-18b inhibitor for $6 \mathrm{~h}$ at $37^{\circ} \mathrm{C}$. Firefly and Renilla luciferase activities were determined $48 \mathrm{~h}$ after transfection at $37^{\circ} \mathrm{C}$ using the Dual-Luciferase Reporter Assay kit (Promega Corporation).

Statistical analysis. All statistical analyses were performed using SPSS software (version 17.0; SPSS, Inc., Chicago, IL, USA). The data are presented as the mean \pm standard deviation. The differences between groups were analyzed using two-sided Student's t-tests. $\mathrm{P}<0.05$ was considered to 
Table I. Association of miR-18b expression level with clinicopathological features in patients with ovarian cancer.

\begin{tabular}{|c|c|c|c|c|c|}
\hline \multirow[b]{2}{*}{ Group } & \multirow[b]{2}{*}{$\mathrm{n}$} & \multicolumn{2}{|c|}{$\begin{array}{c}\text { miR-18b } \\
\text { expression level }\end{array}$} & \multirow[b]{2}{*}{ Pearson's $\chi^{2}$} & \multirow[b]{2}{*}{ P-value } \\
\hline & & Low & High & & \\
\hline Age, years & & & & 0.031 & 0.861 \\
\hline$<50$ & 25 & 12 & 13 & & \\
\hline$\geq 50$ & 35 & 16 & 19 & & \\
\hline Tumor grade & & & & 7.890 & 0.005 \\
\hline G1-G2 & 27 & 18 & 9 & & \\
\hline G3 & 33 & 10 & 23 & & \\
\hline Lymph node metastasis & & & & 15.654 & $<0.001$ \\
\hline Negative & 14 & 13 & 1 & & \\
\hline Positive & 46 & 15 & 31 & & \\
\hline
\end{tabular}

Table II. Primers used in reverse transcription-quantitative polymerase chain reaction analysis.

\begin{tabular}{lll}
\hline Gene symbol & Forward sequence (5'-3') & Reverse sequence (5'-3') \\
\hline miR-18b & GCAGTTAGTGAAGCAGCTTAGA & Universal primer \\
U6 & CTCGCTTCGGCAGCACA & ACGCTTCACGAATTTGCGT \\
PTEN & GCGTGCAGATAATGACAAGG & GGATTTGACGGCTCCTCTAC \\
GAPDH & CAAGGTCATCCATGACAACTTTG & GTCCACCACCCTGTTGCTGTAG \\
\hline
\end{tabular}

miR, microRNA; PTEN, phosphatase and tensin homolog.

indicate a statistically significant difference. All experiments were performed $\geq 3$ times.

\section{Results}

miR-18b is upregulated in human OC tissues and cell lines. To determine the miR-18b expression level in OC, 60 pairs of human $\mathrm{OC}$ tissues and matched normal ovarian tissues were analyzed using RT-qPCR. As presented in Fig. 1A, the expression level of miR-18b was significantly increased in OC tissues, compared with the normal ovarian tissues $(\mathrm{P}<0.05)$. In addition, for the clinicopathological correlation analysis, the relative higher expression level of miR-18b was positively associated with advanced tumor grade and lymph node metastasis, but not with age (Table I). Furthermore, the miR-18b expression level in OC cells was also detected using RT-qPCR. Of note, its expression level was also upregulated in ES-2 $(\mathrm{P}<0.05)$ and HO8910 $(\mathrm{P}<0.05)$ cells, in comparison with in the HOSE human normal ovarian epithelial cells (Fig. 1B). These results suggested that miR-18b may act as an oncogene in $\mathrm{OC}$ progression.

Upregulation of miR-18b promotes OC cell migration. In order to identify the role of miR-18b in OC, miR-18b mimic or mimic negative control, and miR-18b inhibitor or inhibitor negative control were transfected into ES-2 and HO8910 cells. First, RT-qPCR was performed to assess the transfection efficiency in OC cells. The expression levels of miR-18b in
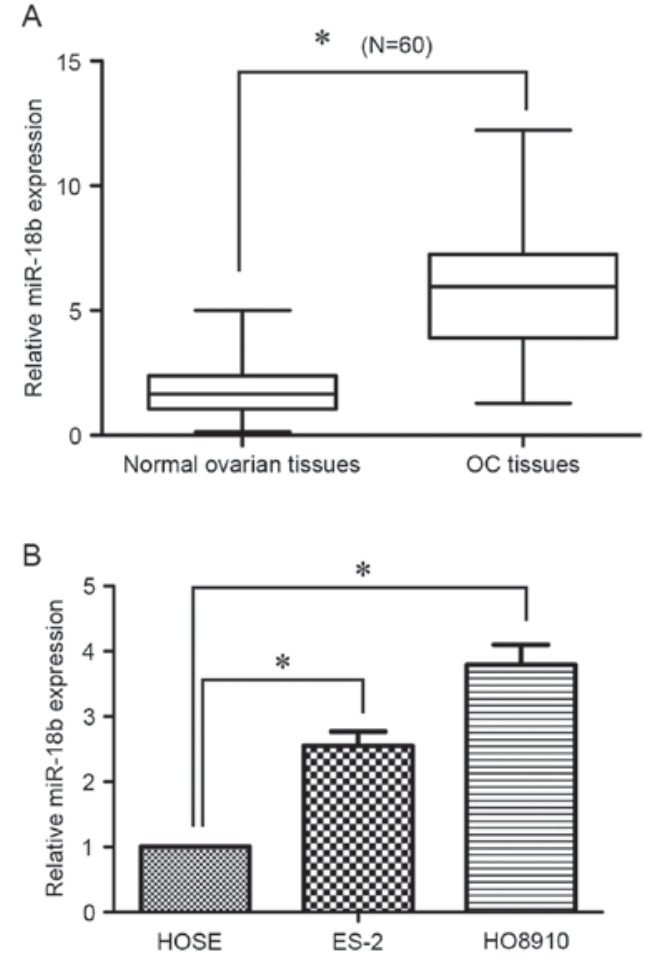

Figure 1. miR-18b is upregulated in human OC tissues and cell lines. (A) Reverse transcription-quantitative polymerase chain reaction analysis of the expression levels of miR-18b in 60 pairs of OC tissues and matched normal ovarian tissues. U6 small nuclear RNA was used as an endogenous control. (B) Upregulation of miR-18b expression in OC cell lines. All data are presented as the mean $\pm \mathrm{SD}(\mathrm{n}=3)$. ${ }^{*} \mathrm{P}<0.05$. OC, ovarian cancer; miR, microRNA. 
A

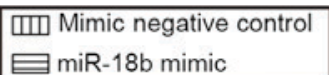
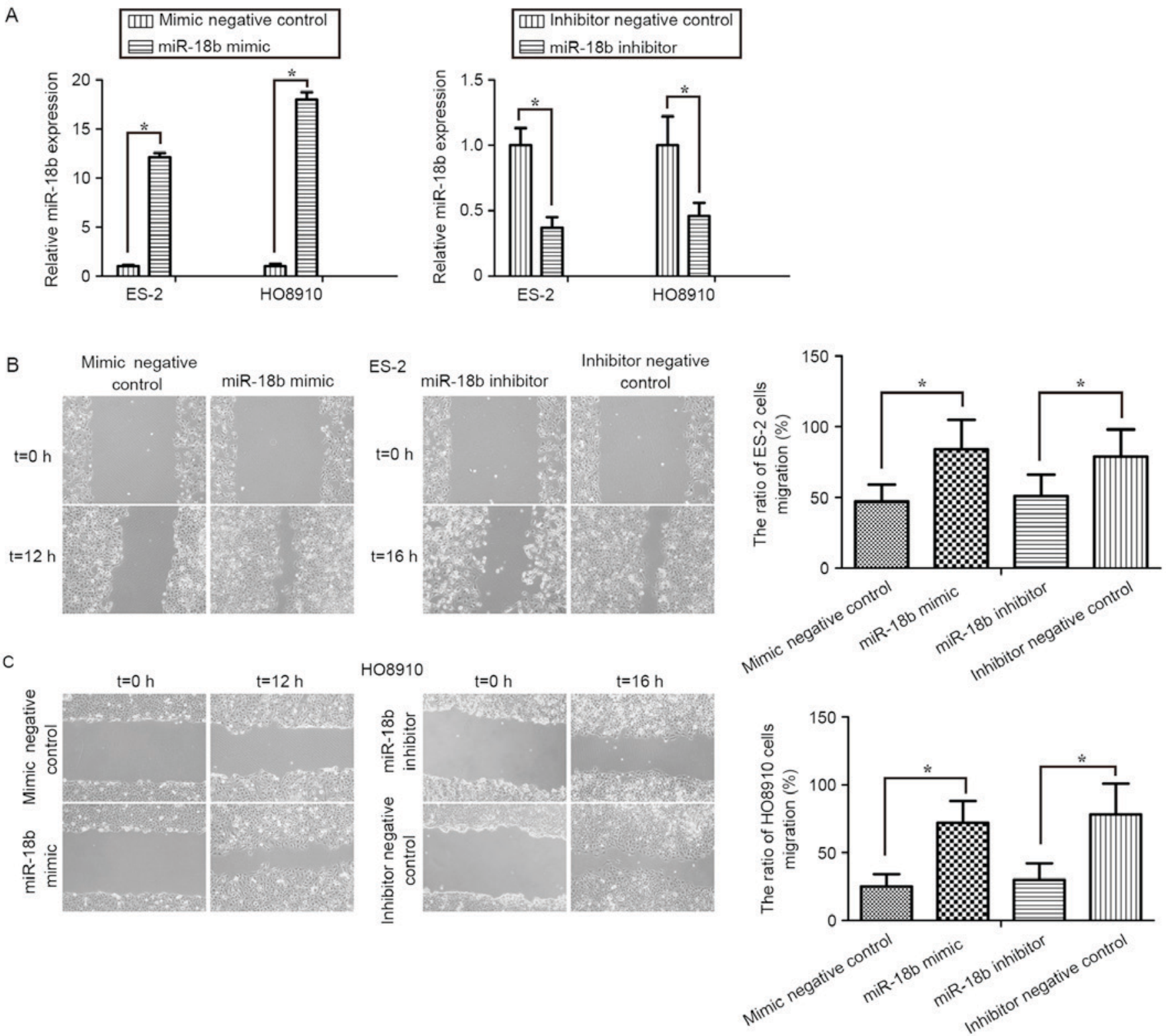

Figure 2. Upregulation of miR-18b promotes OC cell migration. (A) Relative miR-18b expression levels were determined by reverse transcription-quantitative polymerase chain reaction analysis following miR-18b mimic or miR-18b inhibitor transfection in ES-2 and HO8910 cells. (B) Migratory effect of miR-18b mimic or miR-18b inhibitor-treated ES-2 cells. (C) Treatment with miR-18b inhibitor induced a significant suppression in the migratory activities of HO8910, whereas overexpression of miR-18b markedly promoted cell migration. All experiments were performed in triplicate. " $\mathrm{P}<0.05$. OC, ovarian cancer; miR, microRNA.

the ES-2 and HO8910 cells treated with miR-18b mimic were significantly increased, whereas its expression level was markedly decreased following treatment with the miR-18b inhibitor $(\mathrm{P}<0.05$; Fig. 2A).

The effect of miR-18b on OC cell migration was assessed by performing wound healing assays. As presented in Fig. 2B and C, treatment with miR-18b mimic induced a significant increase in the migratory activity of ES-2 $(\mathrm{P}<0.05)$ and HO8910 $(\mathrm{P}<0.05)$ cells, whereas transfection with miR-18b inhibitor exhibited a marked decrease in cell migratory levels $(\mathrm{P}<0.05)$. These results clearly suggested that miR-18b may activate OC cell migration.

Upregulation of miR-18b promotes OC cells invasion. The effect of miR-18b on OC cell invasion was assessed using
Transwell assays. The results revealed that inhibition of miR-18b expression by an inhibitor repressed invasion of ES-2 and HO8910 cells ( $\mathrm{P}<0.05$; Fig. 3A). Conversely, overexpression of miR-18b markedly promoted the invasive activity of OC cells $(\mathrm{P}<0.05$; Fig. 3B). These results further suggested that miR-18b acted as an oncogene in OC progression and development.

PTEN is a direct target of miR-18b in OC cells. To clarify the molecular mechanism underlying miR-18b activity in OC cell migration and invasion, bioinformatics analysis was performed to identify potential targets of miR-18b. Among those targets predicted, PTEN was selected for further research. Two luciferase reporters, one containing wild-type PTEN 3'-UTR (psiCHECK-2-PTEN-WT) with the 
A

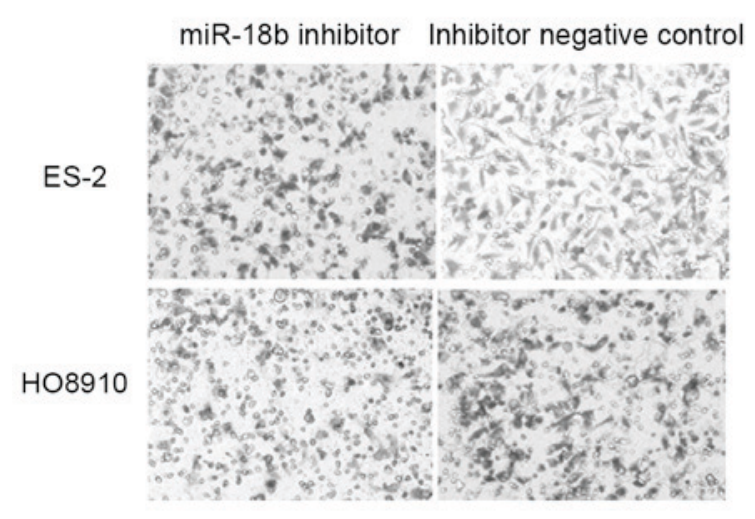

B

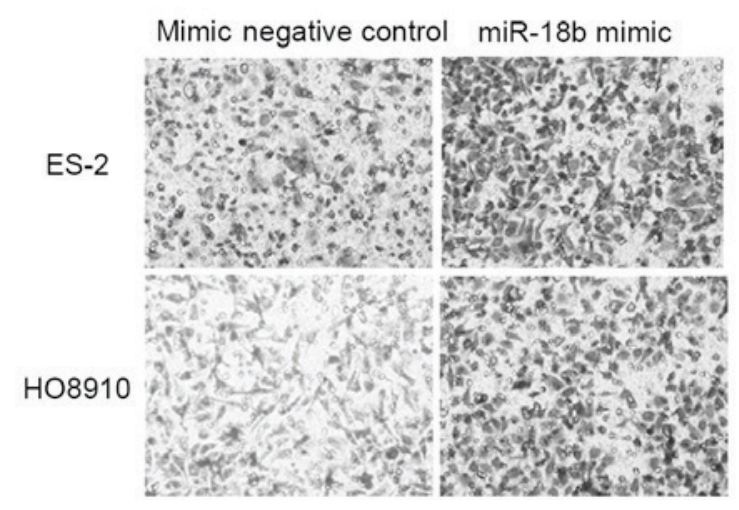

एس miR-18b inhibitor

EInhibitor negative control

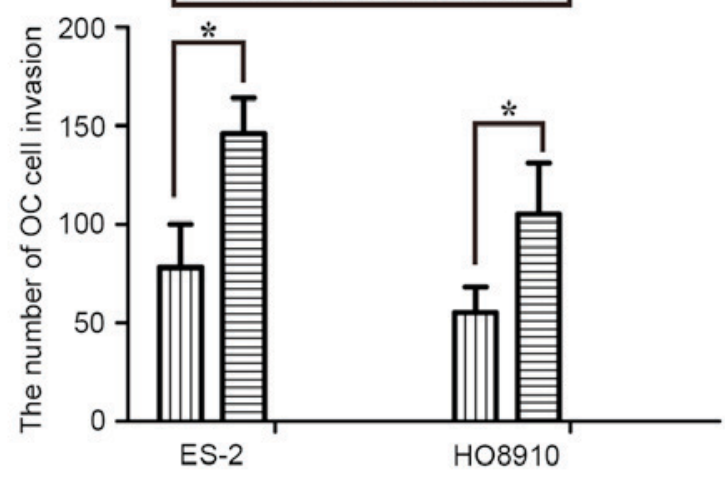

एس] Mimic negative control

miR-18b mimic

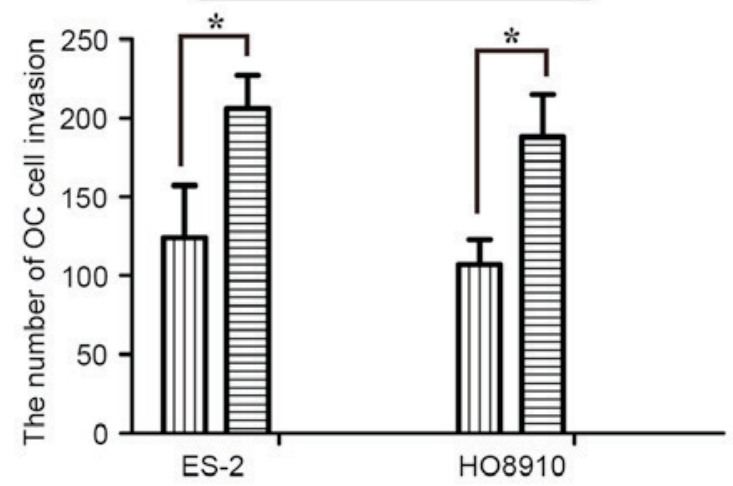

Figure 3. Upregulation of miR-18b promotes OC cell invasion. (A) Transwell assays indicated marked cell invasion inhibition in miR-18b inhibitor-treated ES-2 and HO8910 cells, compared with the inhibitor negative control-treated cells. (B) Invasive effect of miR-18b mimic- or mimic negative control-transfected ES-2 and HO8910 cells. ${ }^{*} \mathrm{P}<0.05$. OC, ovarian cancer; miR, microRNA.

miR-18b-binding sites and another containing mutant PTEN 3'-UTR (psiCHECK-2-PTEN-MUT), were constructed and used to explore whether PTEN is a direct target of miR-18b (Fig. 4A). In luciferase reporter assay, transfection of miR-18b mimic significantly suppressed the luciferase activities, as compared with the mimic control, but did not alter the luciferase activities of the mutant reporter plasmid. Conversely, inhibition of miR-18b endogenous expression induced a marked increase in luciferase activities, compared with the inhibitor negative control ( $\mathrm{P}<0.05$; Fig. 4B).

RT-qPCR and western blot analyses demonstrated that knockdown of miR-18b induced a significant decrease in PTEN mRNA and protein expression levels in ES-2 and HO8910 cells, whereas silencing of miR-18b increased the PTEN expression level $(\mathrm{P}<0.05$; Fig. 4C). The results of the present study demonstrated that PTEN was a direct target of miR-18b in OC cells.

\section{Discussion}

Recent studies have revealed that miRNAs serve key roles in cancer progression and potentially serve as novel biomarkers for the prediction and treatment in various types of human cancer (28-30). The aim of the present study was to clarify the biological function of miR-18b in human OC. The preliminary experiments demonstrated that miR-18b was highly expressed in OC tissues and cell lines, compared with in normal ovarian tissues and ovarian epithelial cells. The relatively increased expression level of miR-18b was positively associated with advanced tumor grade and lymph node metastasis, which suggested that upregulation of miR-18b may be involved in OC metastasis. Exogenous knockdown of miR-18b expression markedly inhibited OC cell migration and invasion activities, whereas overexpression of miR-18b promoted the migration and invasion of OC cells. Furthermore, miR-18b inhibited PTEN expression by directly targeting its 3'-UTR.

Recent studies have provided abundant evidence that miR-18b functions as onco-miRNAs in numerous types of human cancer. For instance, upregulation of miR-18b identified patients with mantle cell lymphoma with poor outcome and improved the mantle cell lymphoma prognostic indicator-B by decreasing the proliferation rate of mantle cell lymphoma cells (31). miRNA-18b was highly expressed in breast cancer and modulated gene expression levels involved in cell migration (22). The expression level of miR-18b in hepatocellular carcinoma was associated with the grade of malignancy and prognosis (26). The results of the present study have revealed that miR-18b was significantly upregulated and promoted human $\mathrm{OC}$ cell migration and invasion. Therefore, the results of the present study also support the view that miR-18b acts as an oncogenic miRNA in OC. 
A

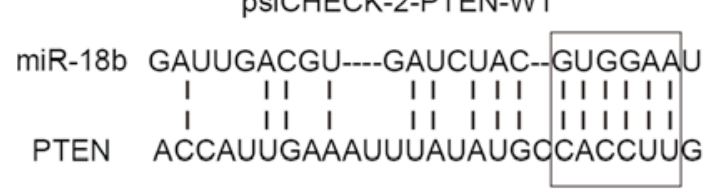

B
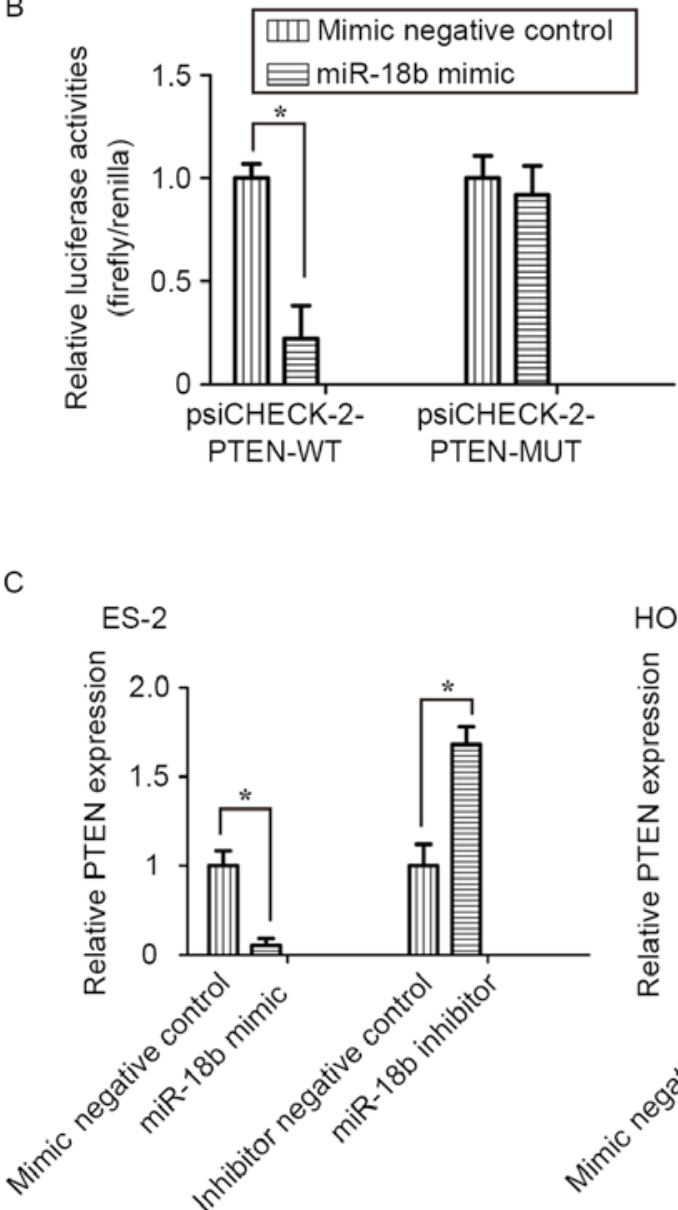

HO8910

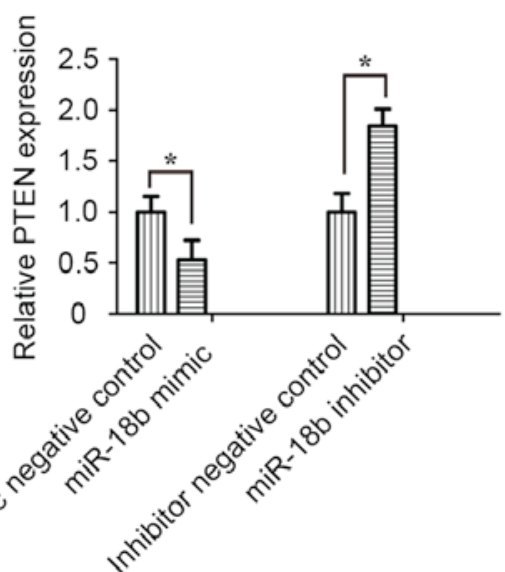

psiCHECK-2-PTEN-MUT

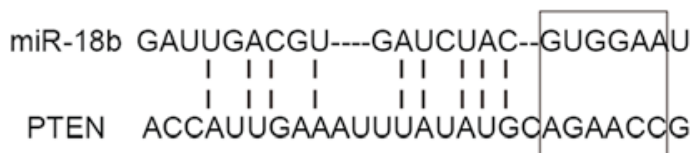

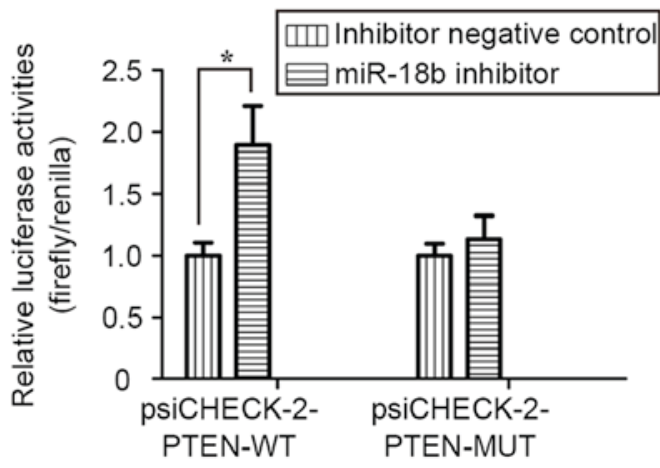

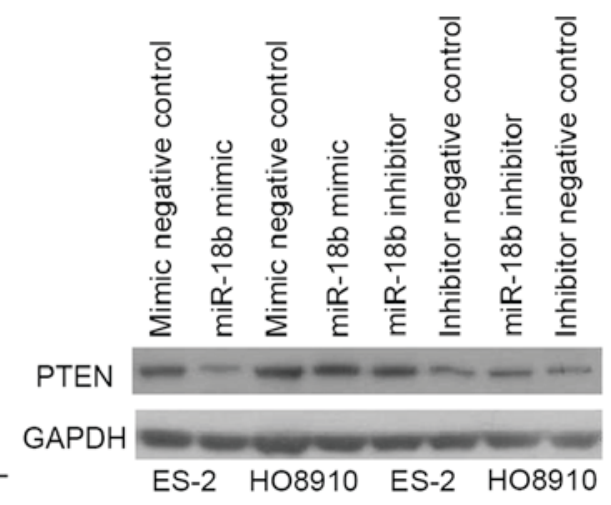

Figure 4. PTEN is a direct target of miR-18b in OC cells. (A) Sequences of miR-18b-binding sites within the PTEN mRNA 3'UTRs. (B) Effect of miR-18b on psiCHECK-2-PTEN-WT and psiCHECK-2-PTEN-MUT luciferase reporter plasmids. (C) Reverse transcription-quantitative polymerase chain reaction and western blotting analyses of the PTEN expression level with GAPDH used as an internal control. Results are presented as the mean \pm standard deviation of three measurements. "P<0.05. PTEN, phosphatase and tensin homolog; OC, ovarian cancer; miR, microRNA; UTR, untranslated region; WT, wild-type; MUT, mutant.

miRNAs typically exert their functions by inhibiting the expression levels of target gene mRNA, therefore the further aim of the present study was to identify miR-18b target genes in OC. PTEN was predicted as a critical downstream target gene using various prediction algorithms $(32,33)$. PTEN was identified as a tumor suppressor gene located on chromosome 10 (34). In recent years, PTEN has gained particular attention for its critical role in multiple types of cancer. Numerous previous studies have demonstrated that low expression levels of PTEN were associated with poor prognosis and chemoresistance in OC $(35,36)$.

In the present study, luciferase reporter assays revealed that miR-18b induced a significant decrease in the luciferase activities of the psiCHECK-2-PTEN-WT reporter, but did not affect the mutant reporter activities. Of note, transfection of miR-18b mimic decreased the PTEN expression level in OC cells. In view of these results, it is proposed that miR-18b downregulates
PTEN gene expression by directly binding to its 3'-UTR. The results of the present study revealed for the first time, to the best of our knowledge, that miR-18b-induced cell migration and invasion may be mediated by targeting PTEN.

In conclusion, the results of the present study provided novel evidence that miR-18b promoted the migration and invasion of OC cells by directly targeting PTEN, which suggested that miR-18b may be a novel promising biomarker for OC prognosis and treatment.

\section{Acknowledgements}

The present study was supported by the National Science and Technology Pillar Program during the Twelfth Five-Year Plan Period (grant no. 2012BAI32B05) and the National Natural Science Foundation of China (grant nos. 81000245 and 81370703). 


\section{References}

1. Siegel R, Ma J, Zou Z and Jemal A: Cancer statistics, 2014. CA Cancer J Clin 64: 9-29, 2014.

2. Jelovac D and Armstrong DK: Recent progress in the diagnosis and treatment of ovarian cancer. CA Cancer J Clin 61: 183-203, 2011.

3. Legge F, Ferrandina G, Salutari V and Scambia G: Biological characterization of ovarian cancer: Prognostic and therapeutic implications. Ann Oncol 16 (Suppl 4): iv95-101, 2005.

4. Pasquinelli AE: MicroRNAs and their targets: Recognition, regulation and an emerging reciprocal relationship. Nat Rev Genet 13: 271-282, 2012.

5. Ambros V: The functions of animal microRNAs. Nature 431: 350-355, 2004

6. Wang H, Cao F, Li X, Miao H, E J, Xing J and Fu CG: miR-320b suppresses cell proliferation by targeting c-Myc in human colorectal cancer cells. BMC Cancer 15: 748, 2015.

7. Tai MC, Kajino T, Nakatochi M, Arima C, Shimada Y, Suzuki M, Miyoshi H2, Yatabe Y3, Yanagisawa K and Takahashi T: miR-342-3p regulates MYC transcriptional activity via direct repression of E2F1 in human lung cancer. Carcinogenesis 36: 1464-1473, 2015

8. Matsuyama R, Okuzaki D, Okada M and Oneyama C: MicroRNA-27b suppresses tumor progression by regulating ARFGEF1 and focal adhesion signaling. Cancer Sci 107: 28-35, 2016.

9. Liu W, An J, Li K and Hou H: MiR-429 regulates gastric cancer cell invasiveness through ZEB proteins. Tumour Biol: Oct 15, 2015 (Epub ahead of print).

10. Li HT, Zhang H, Chen Y, Liu XF and Qian J: MiR-423-3p enhances cell growth through inhibition of p21Cip1/Waf1 in colorectal cancer. Cell Physiol Biochem 37: 1044-1054, 2015.

11. Yu T, Liu L, Li J, Yan M, Lin H, Liu Y, Chu D, Tu H, Gu A and Yao M: MiRNA-10a is upregulated in NSCLC and may promote cancer by targeting PTEN. Oncotarget 6: 30239-30250, 2015.

12. Luo P, Fei J, Zhou J and Zhang W: microRNA-126 suppresses PAK4 expression in ovarian cancer SKOV3 cells. Oncol Lett 9: 2225-2229, 2015

13. Guo J, Xia B, Meng F and Lou G: miR-137 suppresses cell growth in ovarian cancer by targeting AEG-1. Biochem Biophys Res Commun 441: 357-363, 2013.

14. Dong R, Liu X, Zhang Q, Jiang Z, Li Y, Wei Y, Li Y, Yang Q, Liu J, Wei JJ, et al: miR-145 inhibits tumor growth and metastasis by targeting metadherin in high-grade serous ovarian carcinoma Oncotarget 5: 10816-10829, 2014.

15. Wen Z, Zhao S, Liu S, Liu Y, Li X and Li S: MicroRNA-148a inhibits migration and invasion of ovarian cancer cells via targeting sphingosine-1-phosphate receptor 1. Mol Med Rep 12: 3775-3780, 2015

16. Liu R, Liu F, Li L, Sun M and Chen K: MiR-498 regulated FOXO3 expression and inhibited the proliferation of human ovarian cancer cells. Biomed Pharmacother 72: 52-57, 2015.

17. Fan Y, Fan J, Huang L, Ye M, Huang Z, Wang Y, Li Q and Huang J: Increased expression of microRNA-196a predicts poor prognosis in human ovarian carcinoma. Int J Clin Exp Pathol 8: 4132-4137, 2015

18. Liu N, Zhong L, Zeng J, Zhang X, Yang Q, Liao D, Wang Y, Chen G and Wang Y: Upregulation of microRNA-200a associates with tumor proliferation, CSCs phenotype and chemosensitivity in ovarian cancer. Neoplasma 62: 550-559, 2015.

19. Niu K, Shen W, Zhang Y, Zhao Y and Lu Y: MiR-205 promotes motility of ovarian cancer cells via targeting ZEB1. Gene 574 330-336, 2015.
20. Song N, Liu H, Ma X and Zhang S: Placental growth factor promotes metastases of ovarian cancer through MiR-543-regulated MMP7. Cell Physiol Biochem 37: 1104-1112, 2015.

21. Zhu T, Yuan J, Wang Y, Gong C, Xie Y and Li H: MiR-661 contributed to cell proliferation of human ovarian cancer cells by repressing INPP5J expression. Biomed Pharmacother 75: $123-128,2015$.

22. Fonseca-Sanchéz MA, Pérez-Plasencia C, Fernández-Retana J, Arechaga-Ocampo E, Marchat LA, Rodríguez-Cuevas S, Bautista-Piña V, Arellano-Anaya ZE, Flores-Pérez A,Diaz-Chávez J and López-Camarillo C: microRNA-18b is upregulated in breast cancer and modulates genes involved in cell migration. Oncol Rep 30: 2399-2410, 2013

23. Zhang ZZ, Liu X, Wang DQ, Teng MK, Niu LW, Huang AL and Liang Z: Hepatitis B virus and hepatocellular carcinoma at the miRNA level. World J Gastroenterol 17: 3353-3358, 2011.

24. Guo J, Miao Y, Xiao B, Huan R, Jiang Z, Meng D and Wang Y: Differential expression of microRNA species in human gastric cancer versus non-tumorous tissues. J Gastroenterol Hepatol 24 652-657, 2009

25. Wang YX, Zhang XY, Zhang BF, Yang CQ, Chen XM and Gao HJ: Initial study of microRNA expression profiles of colonic cancer without lymph node metastasis. J Dig Dis 11: 50-54, 2010.

26. Murakami Y, Tamori A, Itami S, Tanahashi T, Toyoda H, Tanaka M, Wu W, Brojigin N, Kaneoka Y, Maeda A, et al: The expression level of miR-18b in hepatocellular carcinoma is associated with the grade of malignancy and prognosis. BMC Cancer 13: 99, 2013.

27. Schmittgen TD and Livak KJ: Analyzing real-time PCR data by the comparative C(T) method. Nat Protoc 3: 1101-1108, 2008

28. Guan Y,Chen L, Bao Y,LiZ, Cui R,LiG and Wang Y: Identification of low miR-105 expression as a novel poor prognostic predictor for human glioma. Int J Clin Exp Med 8: 10855-10864, 2015.

29. Dou H, Wang Y, Su G and Zhao S: Decreased plasma let-7c and miR-152 as noninvasive biomarker for non-small-cell lung cancer. Int J Clin Exp Med 8: 9291-9298, 2015.

30. Cai K, Shen F, Cui JH, Yu Y and Pan HQ: Expression of miR-221 in colon cancer correlates with prognosis. Int J Clin Exp Med 8: 2794-2798, 2015

31. Husby S, Ralfkiaer U, Garde C, Zandi R, Ek S, Kolstad A, Jerkeman M, Laurell A, Räty R, Pedersen LB, et al: miR-18b overexpression identifies mantle cell lymphoma patients with poor outcome and improves the MIPI-B prognosticator. Blood 125: 2669-2677, 2015

32. Betel D, Wilson M, Gabow A, Marks DS and Sander C: The microRNA.org resource: Targets and expression. Nucleic Acids Res 36 (Database issue): D149-D153, 2008.

33. Agarwal V, Bell GW, Nam JW and Bartel DP: Predicting effective microRNA target sites in mammalian mRNAs. Elife 4 e05005, 2015.

34. Ying H, Qu D, Liu C, Ying T, Lv J, Jin S and Xu H:Chemoresistance is associated with Beclin-1 and PTEN expression in epithelial ovarian cancers. Oncol Lett 9: 1759-1763, 2015.

35. Cheaib B, Auguste A and Leary A: The PI3K/Akt/mTOR pathway in ovarian cancer: Therapeutic opportunities and challenges. Chin J Cancer 34: 4-16, 2015.

36. Wu H, Wang K, Liu W and Hao Q: PTEN overexpression improves cisplatin-resistance of human ovarian cancer cells through upregulating KRT10 expression. Biochem Biophys Res Commun 444: 141-146, 2014 